\title{
Análisis discursivo del relato empresarial sobre responsabilidad social corporativa. Coordenadas narrativas y prácticas discursivas
}

\author{
Discourse analysis of business narratives about corporate \\ social responsibility. Narrative coordinates and discourse \\ practices
}

Resumen

En este artículo se presentan los resultados del análisis discursivo realizado sobre las producciones verbales elaboradas por Directivos de Responsabilidad Social (DIRSE) para explicar qué son y cómo se organizan sus políticas socialmente responsables.Concretamente, se disecciona el modo en que la élite empresarial española construye las coordenadas narrativas de su relato sobre la responsabilidad social corporativa o empresarial, haciendo especial hincapié en el conjunto de significaciones y maniobras discursivas que las configuran. Para ello, se ha dividido el documento en cuatro epígrafes. En el primero se introduce al lector en la perspectiva adoptada en esta investigación. En el segundo epígrafe se exponen las principales cuestiones de orden metodológico y en el tercero se presentan los resultados. Finalmente, el documento se cierra con una síntesis de las conclusiones alcanzadas.

Palabras clave: análisis del discurso, responsabilidad social corporativa, directivos de RSE, élite empresarial, empresas transnacionales.

\begin{abstract}
In this paper we present the results of the discourse analysis of verbal productions made by Managers of Social Responsibility (DIRSE by its Spanish acronym) to explain what they are and how their socially responsible policies are organized. More specifically, we examine the way that Spanish business elite builds the narrative coordinates of its discourse about corporate social responsibility, with particular emphasis on the set of meanings and discourse manoeuvres that shapes them. In order to do so, we have divided this paper into four sections. In the first one, the reader is introduced to the approach taken for this
\end{abstract}


research. In the second section we reflect the main methodological issues, while the last two sections present respectively the results and conclusions of our analysis.

Keywords: discourse analysis, corporate social responsibility, CSR managers, business elite, transnational corporations.

Se puede decir la verdad siempre que se diga en el espacio de una exterioridad salvaje; pero no se está en la verdad más que obedeciendo a las reglas de una "policía» discursiva que se debe reactivar en cada uno de los discursos

(FouCAULT, 1973:31).

\section{INTRODUCCIÓN}

La responsabilidad social corporativa ${ }^{1}$ es, además de un conjunto heterogéneo de iniciativas empresariales, un artefacto conceptual desbordado de significaciones y sentidos. Su significado hegemónico ha dependido del escenario de fuerzas ideológicas que han determinado, en cada momento, cómo debe ser organizada la economía para controlar el poder de las empresas. Así, las posturas ideológicas más proclives a defender una mayor regulación e intensidad democrática de la economía suelen concebir la RSC como una medida que debe limitar y compensar el poder corporativo. En cambio, aquellas que suelen situarse en el espacio más próximo al libre mercado y a la mercantilización de los derechos sociales tienden a defender una Rsc centrada en crear valor para sus accionistas y grupos de interés o stakeholders, ${ }^{2}$-y que en otro lugar hemos denominado neoliberal (Gil, $2016 a, 2016 b$ ) - . Desde los años setenta hasta hoy, ha predominado en el contexto anglosajón y europeo esta última acepción de la Rsc, que la concibe como una estrategia capaz de reforzar la competitividad de la empresa y, a su vez, crear valor para las sociedades en las que estas operan (Porter y Kramer, 2006, 2011). Una Rsc que siempre es voluntaria y que se define

1 Se empleará la expresión responsabilidad social corporativa (RSC), más propia del mundo anglosajón, en especial de Estados Unidos, como sinónimo de responsabilidad social empresarial (RSE), particularmente utilizada en el contexto europeo-continental. Esta decisión en ningún momento pretende negar las diferencias existentes entre las concepciones y prácticas que caracterizan la RSE de las diferentes regiones, simplemente intenta facilitar la lectura. Se recomiendan los siguientes trabajos para indagar sobre las diferencias citadas: Lozano, Albareda, Ysa, Roscher, y Marcuccio (2005), Matten y Moon (2008), Blowfield y Murray (2008) y Domínguez (2012).

2 El término stakebolder hace referencia a todos aquellos colectivos o partes interesadas que pueden afectar o verse afectados por la corporación empresarial. 
como la obligación de ocuparse de ciertos deberes, asumir ciertas cargas o mantener determinados comportamientos en las esferas del desempeño económico, social y laboral de las empresas. En España, el mundo de los negocios ha defendido mayoritariamente esta noción en todos los espacios públicos y privados de promoción o divulgación en los que ha participado (Gil, 2016a). ${ }^{3}$ No obstante, pocos estudios se han adentrado en el análisis de las ideas, representaciones y estrategias que permiten este posicionamiento, tarea que vamos a presentar en este artículo. Concretamente, nos centraremos en el análisis del campo de la discursividad que el mundo de los negocios construye al significar determinadas prácticas como «socialmente responsables» (Laclau y Mouffe, 1987).

\section{APUNTES METODOLÓGICOS}

El tratamiento de la Rsc como artefacto discursivo ha sido posible por el posicionamiento teórico adoptado a la hora de interpretar el papel del lenguaje en la construcción de la realidad. Este se sitúa dentro de las coordenadas teóricas que la sociología europea y americana dibujaron a finales de la década de los sesenta cuando hicieron suyo el giro lingüístico y determinadas aportaciones de la pragmática lingüística, la etnometodología y la obra de Foucault, entre otras. Estas tradiciones intelectuales -y otras más específicamente sociológicas - favorecieron la eclosión de un conjunto de estrategias analíticas, con orientaciones teóricas y metodológicas diversas, aglutinadas bajo la etiqueta de "análisis del discurso», entre las que se encuentran las utilizadas en este trabajo para construir nuestro objeto de estudio y orientar su análisis (Wetherell, 2001;Antaki, Edwards y Potter, 2003; Conde, 2009; Van Dijk, 2000, Gutiérrez Brito, 2009; Íñiguez, 2011; y Rapley, 2014).

El análisis del relato empresarial que aquí presentamos ha estado guiado por la propuesta elaborada por el investigador Fernando Conde (2009): el Análisis Sociológico del Sistema de Discursos (ASSD). Su carácter espe-

3 Cuando hacemos alusión al «mundo de los negocios» nos referimos al conjunto de escuelas de negocios, asociaciones empresariales, observatorios y corporaciones transnacionales que han incluido el asunto de la responsabilidad social corporativa en sus agendas. Este conjunto heterogéneo de actores ha sido pionero en la implantación y divulgación de medidas de rsc, tanto a escala internacional como nacional. Para el caso de España, el mundo empresarial se adelantó a la acción de promoción del Gobierno Español -iniciada en 2005- con la puesta en práctica de iniciativas socialmente responsables y la conformación de asociaciones para la promoción de la Rse (Perdiguero, 2008; Barañano, 2009, 2010; Maira, 2010, 2012; Maira y Gil, 2011; Ancos y Sánchez-Urán, 2013; Gil, $2016 a, 2016 b)$. 
cíficamente sociológico y, por lo tanto, su sensibilidad para reconstruir el sentido de los discursos mediante un análisis que privilegia el contexto, las relaciones de poder y conflicto, así como las estrategias de los actores implicados (Gordo, 2008; Conde, 2009; Gutiérrez Brito, 2009; Iñ̃iguez, 2011; Alonso, 2013; Rapley, 2014; Flick, 2014); ha sido uno de los principales motivos principales en los que se ha apoyado su elección. Asimismo, también ha sido de suma importancia la capacidad de dicho autor para explicitar los procedimientos que lo componen en un manual publicado por el Centro de Investigaciones Sociológicas. ${ }^{4}$

En el ASSD, en clara consonancia con los planteamientos etnometodológicos, los discursos son definidos como producciones y prácticas sociales que no solo expresan lo que el actor quiere informar, sino que además revelan las jugadas que este despliega en sus interacciones. Estos discursos, según la propuesta escogida, deben ser construidos en el plano teórico por las personas que investigan. Para ello, deben:

Analizar sus elementos, sus componentes, cómo se ordenan y se estructuran, cómo se combinan y se diferencian, a qué orden responden, qué relación guardan con el contexto social, con los propios sujetos de la investigación, cómo reproducen la realidad social y qué tipo de realidad social ayudan a construir, etc. (Conde, 2009:36).

Además, en sintonía con la tradición dialógica rusa, el ASSD enfatiza el carácter sistémico del discurso, lo que se traduce en elaborar teóricamente los discursos que estudia y localizarlos en el mapa o sistema discursivo que lo conforman, ya que todo «discurso se produce y desarrolla en relación con otro discurso al que alude, al que interpela, al que se trata de aproximar o del que se trata de diferenciar» (Conde, 2009: 43). Los principales procedimientos para la interpretación sociológica del sistema de discursos son resumidos por Conde en el análisis de posiciones discursivas, configuraciones narrativas y espacios semánticos. En este trabajo se han llevado a cabo los dos últimos. En el análisis de configuraciones narrativas se descubren las dimensiones de los textos, las cuales funcionan como hilos que tejen la trama del relato. Con este procedimiento se trabaja en el nivel latente de la significación, en él predomina el trabajo de contextualización e interpretación. Los espacios semánticos, en cambio, son «el conjunto de términos sistematizados por relaciones de similitud, contraste, jerarquiza-

4 No podemos decir que esta obra Conde solucione todos los problemas con los que se enfrenta la persona que investiga, pero sí podemos afirmar que su lectura minuciosa y su puesta en práctica, acompañada de la revisión de las investigaciones del autor, le ofrece al analista una guía de gran utilidad. 
ción y proximidad capaces de otorgar sentidos diferenciados a los hechos y cuyo uso presupone una competencia social específica» (Alonso en Conde, 2009: 205). Su análisis requiere adentrarse en la función más referencial del habla.

Los textos principales que configuran la base empírica de este AssD han sido elegidos de las entrevistas realizadas - entre finales de 2008 y 2010- a directivos de RSE (DIRSE) y/o profesionales responsables de este asunto en empresas transnacionales españolas. ${ }^{5}$ Para la selección de los casos se llevó a cabo un muestreo cualitativo desarrollado en dos fases, en donde la segunda corregía a la primera ${ }^{6}$.

En la primera, se desplegó un muestreo puramente intencional concentrado en la búsqueda de perfiles homogéneos de empresas que, además de formar parte de la élite empresarial española, fuesen de las más sobresalientes en materia de Rsc. Lo que nos interesaba era profundizar en el subgrupo de empresas españolas que habían hecho de la RsC una estrategia económica y política, creando, entre otras cosas, redes privadas de cooperación interempresarial relacionadas con la Rsc (Albareda, 2009). No obstante, la conjunción de estos dos criterios se volvió problemática por dos cuestiones fundamentales. Por un lado, nos encontrábamos con el problema del respeto al anonimato asegurado en las entrevistas. ${ }^{7}$ Por otro, el análisis se volvía más fecundo cuando introducíamos textos que procedían de empresas que mantenían un menor grado de adhesión al relato común, lo que se correspondía con la introducción de empresas ajenas a la «cúpula de la RSC».

En una segunda fase, y guiados por el modo de hacer propio del muestreo teórico, se diversificaron los perfiles mediante la introducción de nuevos

5 Las entrevistas seleccionadas fueron producidas en el marco de dos investigaciones multidisciplinares diseñadas para profundizar sobre el fenómeno de la RsC en la Comunidad de Madrid (La Responsabilidad Social Empresarial en las empresas transnacionales españolas con sede central en la Comunidad de Madrid -Fundación Sindical de Estudios de Comisiones Obreras, 2008-) y en el conjunto del territorio español (La Responsabilidad Social de las Empresas en España: conceptos, actores $e$ instrumentos -Ministerio de Educación y Ciencia, 2007/2010-). Desde aquí queremos agradecer a sus investigadores principales el habernos permitido utilizar estos materiales con fines académicos y, a los informantes, su inestimable generosidad y paciencia.

6 La primera fase estuvo orientada por el modo de hacer que caracteriza al muestreo intencional y la segunda, al teórico. El muestreo intencional se diseña con anterioridad al trabajo de campo, siguiendo las orientaciones que la literatura y el conocimiento ofrecen. En cambio, en el teórico se eligen los criterios muestrales a medida que el material producido por el investigador se va analizando, basándose en los códigos y categorías que emergen en dicho proceso (Patton, 1990; Glaser y Strauss, 1967; Bonilla-Castro y Rodríguez, 2005; Fernández Rodríguez, 2004, 2007).

$7 \mathrm{Al}$ ser un grupo tan específico -y tan top ten- la identificación de las organizaciones empresariales era muy evidente. Estas no se diluían entre las dos mil empresas transnacionales que parecen existir en España, ya que estamos hablando de empresas que no solo forman parte del IBEx 35, sino que también se encuentran en rankings tan exclusivos como el Fortune Global-500 o el Global 500 del Financial Times. 
casos más típicos que homogéneos. Para ello, introdujimos el criterio "diversidad sectorial» combinando los sectores más importantes del mundo de los negocios multinacionales (construcción, financiero, telecomunicaciones, energía y servicios -Guillén y García, 2007-), con aquellos que componen los seis sectores básicos de la clasificación sectorial bursátil del IBEX 35 según la modificación de 1 de enero de 2005 (petróleo y energía; materiales básicos, industria y construcción; bienes de consumo; servicios de consumo; servicios financieros e inmobiliarias; tecnología y telecomunicaciones).

En definitiva, seleccionamos doce empresas transnacionales (ETN) para estudiar principalmente mediante sus entrevistas el carácter pragmático de sus narraciones (Tabla 1); aunque también se incluyeron en el material de análisis extractos seleccionados de los informes de RSC (2013) de las empresas escogidas y parte del material escrito y/o publicado (manuales, artículos, blogs y entrevistas) por la élite empresarial española sobre el tema que nos ocupa.

Tabla 1

Casos seleccionados de entre la élite empresarial trasnacional, ordenados por sectores

\begin{tabular}{|c|c|c|c|c|}
\hline $\begin{array}{l}\text { Construcción } \\
\text { e industrial }\end{array}$ & $\begin{array}{l}\text { Petróleo } \\
\text { y Energía }\end{array}$ & $\begin{array}{c}\text { Servicios } \\
\text { Financieros } \\
\text { e Inmobiliarios }\end{array}$ & $\begin{array}{l}\text { Bienes de } \\
\text { consumo }\end{array}$ & $\begin{array}{c}\text { Tecnología } \\
\text { y Telecomunica- } \\
\text { ciones }\end{array}$ \\
\hline Conein1 & Pegas1 & SEFIN1 & BIECON1 & Tecitel 1 \\
\hline \multirow[t]{2}{*}{ Conein2 } & Pegas2 & SEFIN2 & BIECON2 & Tecitel 2 \\
\hline & & SEFIN3 & BIECON3 & \\
\hline
\end{tabular}

\section{RESULTADOS}

\subsection{Coordenadas y maniobras discursivas}

Todo lo que cuentan los y las DIRSE sobre la Rsc se mueve dentro de unas coordenadas narrativas concretas, las cuales configuran la matriz discursiva de la noción empresarial nsc. Dicha matriz, representada en la Figura 1, está construida sobre dos vectores o dimensiones que los profesionales imponen de un modo explícito en sus narraciones mediante dos maniobras discursivas 
generalizadas: una es la definición de la Rsc como aquello que no es acción social, y la otra, su incardinación en el campo semántico de la ganancia.

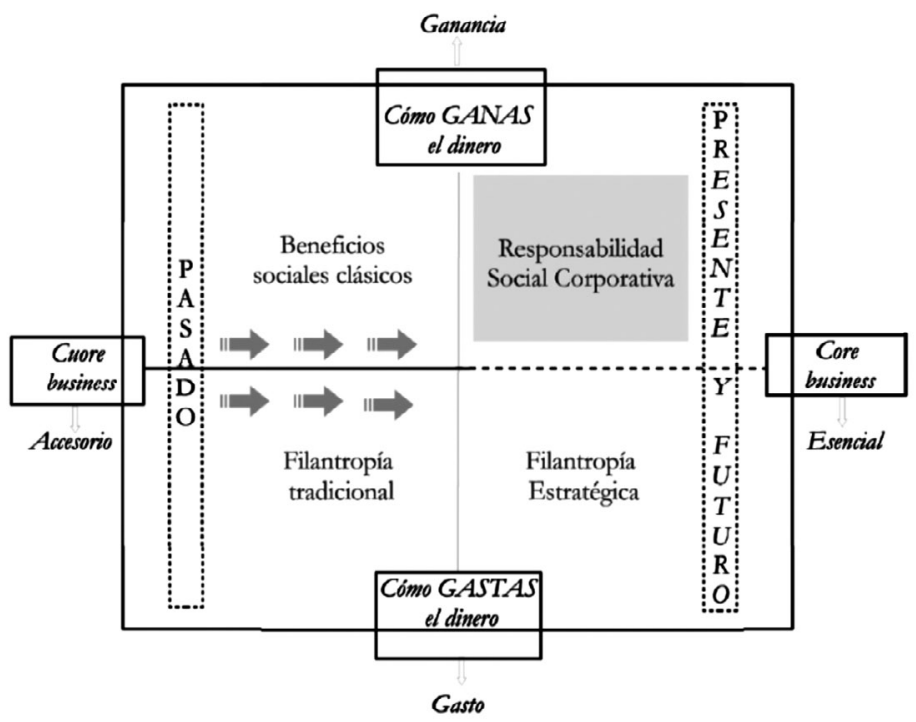

Figura 1

Matriz discursiva de la noción empresarial RSC

Como puede verse, el vector horizontal está representado por el continuun que hemos denominado cuore business/core business, ${ }^{8}$ donde el primero representa al pasado y el segundo al presente. Esta es una dimensión no sólo topológica, sino también cronológica, sobre la que se inscribe la práctica discursiva de definir la Rsc de un modo negativo (como aquello que no es acción social). Esta práctica, como decimos, está presente tanto en nuestro principal corpus de textos para el análisis como en el propio material creado y/o compartido por los responsables de RSC.

Entre las entrevistas realizadas nos encontramos con un número importante de imágenes elaboradas para ilustrar lo que es la Rsc basándose en esta diferencia. Concretamente, nuestros entrevistados dicen cosas como que la acción social es únicamente la «guinda del pastel» (donde el pastel es la RSC)

8 El juego de palabras (cuore/core) lo hemos tomado prestado de un artículo elaborado por la directora de sostenibilidad de Ikea Ibérica SA, Mercedes Gutiérrez, publicado en diarioresponsable.com (2015). 
o el «primer escalón» de una escalera que te lleva a la integración de tus compromisos en la estrategia del negocio (es decir, que te lleva al circuito de la RSC) o, también, que la filantropía es la responsabilidad empresarial «no inteligente» frente a la Rsc, que sí lo es, o que la responsabilidad social es como la información genética que está en el ADN de la empresa. Sea como fuere, en cada una de las metáforas utilizadas por los y las representantes de las empresas hay una identificación de un objeto, en este caso la RSE, con otro, en virtud de lo que estos consideran una relación de semejanza: una tarta, una escalera, un coeficiente intelectual o la información genética de un organismo vivo.

Entre todas ellas existe una configuración narrativa, latente y compartida, que permite evidenciar las connotaciones expresivas de la idea representada y que podemos explicar a través del par conceptual accesorio/ esencial mostrado en la Figura 1. Lo esencial hace referencia al negocio principal de la empresa, o a lo que en el lenguaje del management se conoce como core business, y lo accesorio, a todo aquello que tiene un carácter secundario o dependiente de este. Dicho con otras palabras, lo accesorio lo configuran las iniciativas sociales (como la filantropía o los balances sociales), carentes de estrategia, desvinculadas del sector, tipo de negocio o actividad, pero «llenas de corazón» (cuore business).

El segundo vector que termina de sostener la matriz discursiva de la noción empresarial, es el representado por el eje ganancia/gasto. Aquí el extremo superior (ganancia) está emparentado con la Rsc y el inferior (gasto) con la acción social. A continuación, presentamos dos clarificadores extractos de entrevistas en los que este vector narrativo es claro y no está disperso a lo largo del texto:

Yo creo que, hoy por hoy, el reto está en cómo una compañía integra esta idea de dar compromisos y responder de la mejor manera posible a todos los grupos de interés, de forma íntegra y transparente, y de cómo integra todos estos elementos dentro de sus procesos diarios de gestión, yo creo que ese es el gran reto.Y cómo pasamos lo que sería de una responsabilidad más social, más basada en la acción social, en lo que es una responsabilidad de las operaciones de tu negocio directamente, ¿no? Yo creo que ese es el gran reto en el que estamos grandes compañías, yo creo que, de las multinacionales españolas, pues estamos todas trabajando en esta línea y que supone un gran salto, ¿no?Y que supone no tanto en qué te gastas el dinero que ganas, sino en cómo lo ganas, ¿no? Ese es el gran desafío que tenemos las compañías ahora (SEFIN1).

[la RSC significa que] es legítimo para las empresas que actúen buscando el beneficio, pero [...] de lo que se trata es de buscar cuál es la calidad de ese beneficio, o sea, ese beneficio puede conseguirse legítimamente, pero lo que hay que mirar cómo se ha conseguido y básicamente lo que se mira es cómo se ha conseguido en relación a su entorno natural, cómo lo ha conseguido en relación al medio ambiente en cuanto a los impactos producidos y cómo lo ha conseguido en relación a proveedores, clientes, empleados, organismos... (PEGAs1). 
En suma, el discurso empresarial sobre la RSC no oculta su visión economicista, la presenta como la forma más coherente y honesta de responder a los grupos de interés y reflejar así su compromiso social bajo la siguiente lógica: «Si aceptamos que el objetivo y fundamento de la corporación es hacer dinero y no música dulce (como diría Theodore Levitt, 1958), el modo genuino y verdaderamente creíble de mostrar nuestro compromiso social es supeditándolo al motivo central de nuestra existencia: el beneficio».Y es que la élite empresarial española asume que:

al final lo que se está pidiendo a las empresas es un comportamiento diferente, no se les está pidiendo a las empresas que dejen de ganar dinero, que es su primera obligación, una sociedad con ánimo de lucro tiene que cumplir con su naturaleza mercantil y esa es su primera responsabilidad (SEFIN3).

Esta defensa de la necesidad de retorno de la RsC y de su importancia como forma de asegurar su legitimidad conecta con la clásica idea de que la persecución del interés privado contribuye al interés general y que, por lo tanto, las actividades económicas lucrativas incluyen una moral consecuencialista que garantiza su bondad (Boltanski y Chiapello, 2002; Álvarez-Uría y Varela, 2004). No obstante, difiere de esta en que el carácter moral del lucro ya no está en los efectos derivados de la creación de riqueza, la cual es considerada por sí misma una acción en pro del bien común, sino que la propia iniciativa empresarial ya implica un valor moral, ya que ofrece un negocio donde hay una expectativa, necesidad o un problema social.

Los directivos y profesionales de la Rsc entrevistados también se han servido de otras maniobras discursivas, más elaboradas que las metáforas comentadas, para distanciarse de la tan difamada acción social. Una tiene que ver con el modo de nominar la Rsc y la otra con la expulsión de todo lenguaje moral del discurso empresarial.

Respecto al modo de nombrar la Rsc, hacemos referencia a la decisión de extraer la «\$» de la expresión responsabilidad social corporativa y su acrónimo. En nuestra muestra, más de la mitad de las empresas analizadas han decidido nominar este nuevo modo de hacer negocio como responsabilidad corporativa (RC) con el propósito de evitar la supuesta colonización de sentido que el adjetivo «social» produce sobre la noción. El siguiente diálogo entre la entrevistadora y la persona entrevistada no es quizás el que más claramente detalle esta decisión empresarial, pero sí el que mejor refleja el grado de cristalización del debate sobre la nominación y sus implicaciones: 
Respuesta: [Nosotros lo llamamos responsabilidad corporativa.

Entrevistadora: Y sobre eso también, ¿por qué lo llaman responsabilidad corporativa, por qué han quitado el tema social?

Respuesta: Se quitó desde el principio. Porque no es que quites el tema social. Si se llama social parece que quitas la parte del resto, ¿no?] (CONEIN1).

Como se puede interpretar, lo que se comunica en este breve diálogo es mucho más de lo que cada una de las personas implicadas dicen. Por una parte, se da por hecho que la nominación forma parte de la definición, o lo que es lo mismo, y como lo expresaría Laclau (2005), que la nominación es una forma de fijar el sentido de la responsabilidad corporativa. Por otra, se puede detectar la puesta en juego por parte de la persona entrevistada de un argumento, elaborado colectivamente, sobre el que se ha reflexionado.

La justificación esgrimida por las corporaciones para argumentar la apuesta por el nombre responsabilidad corporativa, gira alrededor de la búsqueda de coherencia con el sentido economicista (win-win) que pretenden imprimirle y el deseo de edificar ese "capitalismo con rostro humano» o caring capitalism (Sklair, 2001) que los nuevos tiempos parecen exigir a la empresa. ${ }^{9}$

Respecto a la segunda maniobra citada, tanto las empresas que incluyen la «S» como aquellas que la expulsan, evitan en todo momento el uso del lenguaje moral. De hecho, sólo podemos detectar argumentos o conceptos relacionados con el ámbito de las emociones morales o los valores (culpa, remordimiento, vergüenza, bondad, solidaridad o justicia) si nos fijamos en aquello que no se dice, que no se nombra, que se expulsa de lo decible. Sólo de esta manera podemos reparar en la resistencia de las corporaciones a considerarse culpables, o en el modo en que ridiculizan todo lo que tenga que ver con el altruismo y la solidaridad, tal y como veremos a continuación.

La configuración del sentido empresarial alrededor de los dos ejes citados no agota la naturaleza de las ideas excluidas en torno al campo semántico de la acción social o la filantropía, sino que también cierra las puertas a aquellas otras que se sitúan en una configuración política más próxima a una regulación mixta de la economía y a una democracia social, mediante un ejercicio velado de expulsión. No obstante, esta práctica no evita el conflicto, aunque lo sortee. Así, la Asociación Española de Directivos de Responsabilidad Socia ${ }^{10}$ reconoce en uno de sus documentos (2014) su preocu-

9 Como nos recuerda Albareda, este capitalismo contrasta con el capitalismo salvaje que «caracterizó la actitud de los principales altos directivos de las empresas en la década de 1980, que tenían una ideología basada en el neoliberalismo conservador» (2009: 338).

10 La asociación DIRSE es la primera agrupación profesional de RSE en España. Se creó en abril de 2013 con el 
pación por la falta de acuerdo en todo lo relacionado con la RSC, incluida la forma de nominarla, lo que manifiesta no solo «una tediosa discrepancia terminológica» sino que sobre todo - y esto es más grave- queda patente una diferencia de más calado: un disentimiento epistemológico que apunta a la comprensión de lo que el fenómeno de la empresa significa en el concierto social; y a la interpretación de lo que implica y exige una gestión empresarial responsable y auténticamente competitiva. Y ello tal vez sea así porque, como ya se ha señalado (Andreu y Fernández, 2011), en los últimos tiempos se ha ido generando un indeseable efecto halo en torno a la RSE y a la tarea propia del DIRSE. Pues, en efecto, tomando la parte por el todo e incluso yendo de lo esencial - el núcleo duro del modelo del negocio, el core business - a lo periférico - la acción social de la empresa, la filantropía empresarial-, la RSE ha venido a quedar clausurada y como «secuestrada» en unos límites mucho más estrechos de lo que sería deseable.

La metáfora del secuestro hace alusión explícita al diagnóstico que los profesores (y directivo para el caso del primero) Andreu y Fernández formulan sobre los problemas que ha terminado por presentar la Rsc para desprenderse de las ideas relacionadas con la caridad y la filantropía.Tanto es así que estos autores indican «la necesidad de evolucionar el concepto de Responsabilidad Social Corporativa (RSC) hacia la idea de Sostenibilidad Corporativa» (2011:5). ${ }^{11}$ Una necesidad que parte del firme convencimiento de que «en términos de naming y de posicionamiento, será más difícil desprender a la Rsc de su efecto halo vinculado a lo social, que darle nuevos contenidos al concepto de Sostenibilidad Corporativa, aun cuando esta figura pudiera estar inicialmente más vinculada a lo medioambiental» (Andreu y Fernández, 2011: 6).

Sin embargo, cuando ahondamos en las premisas que los autores proponen para que el concepto de Sostenibilidad Corporativa sea un éxito nos damos cuenta de que, en realidad, pretenden mucho más que distinguirse de la acción social tradicional. ${ }^{12}$ Veamos cuáles son estas premisas:

doble propósito de, por un lado, «conocer, definir y delimitar el estado de la profesión de los directivos de la RSE con rigor y, por tanto, dignificar su función directiva y su desempeño profesional; $y$, por otro, «detectar y trasladar -así como generar en un futuro- al ámbito español las tendencias de otras agrupaciones homólogas en otros países que han servido de inspiración» (www.dirse.es/quienes-somos).

11 Andreu Pinillos, en alguna ocasión llamado el Decano de la RsE en España, es miembro del Consejo Estatal de Responsabilidad Social Empresarial, patrono de la Cátedra de Ética Económica y Empresarial de la Universidad Pontificia de Comillas y miembro del Consejo de Stakeholders de Global Reporting Initiative. Asimismo, en la actualidad es Visiting Professor de la School of Economics \& Business Administration de la Universidad de Navarra y autor del blog www.albertoandreu.com. José Luis Fernández Fernández es Director de la Cátedra Javier Benjumea de Ética Económica y Empresarial del ICADE (Universidad Pontificia Comillas).

12 El análisis de la propuesta de estos autores es pertinente en la medida en que ha sido utilizado 
La primera de ellas pasa por un cambio de lenguaje de los profesionales de la Rsc. Para empezar, hay que abandonar eso que algunos llaman «buenismo» y que se traduce en esa frase que dice que «hay que devolver a la sociedad lo que la sociedad nos ha dado». Este concepto, basado especialmente en la filantropía, es difícil de mantener en una época de crisis. E incluso, si se nos permite, parece que la empresa tenga que pedir perdón por ganar dinero.

La segunda premisa pasa por construir el modelo de negocio (business case) de la sostenibilidad. Como afirman Mikael Hagström, Jonathan Hornby y Alissa A. Farrel en su trabajo The Evolving Science of Managing for Sustainability: Using ICT to Optimize Environmental and Economic Outcomes, los directivos de todos los sectores coinciden en que la definición del business case es el factor más importante en el éxito. Nadie puede presionar para obtener fondos con los que invertir en sostenibilidad si no se puede probar, de una manera u otra, el rendimiento de la inversión.

La tercera premisa implica un cambio en el modelo de gestión de la Rsc. La inversión en proyectos sociales debe hacerse de la misma manera en que se invierte en I+D [...].

La cuarta y última premisa exige a la sostenibilidad superar su origen medioambiental [...] (2011: 16-17).

En primer lugar, las premisas presentadas parecen más una respuesta a los actores críticos con la concepción economicista de la RSE que una réplica a las empresas, profesionales y otros profanos que la confunden con la acción social. Concretamente, parecen defenderse de aquellas posiciones teóricas y sociales que exigen controlar y/o supeditar la lógica del beneficio privado a la del interés colectivo. Si no fuese así, no sería comprensible ni pertinente la defensa de la primacía de la lógica del beneficio y su cálculo maximizador en cualquier decisión empresarial. Esta interpretación se refuerza cuando detectamos en las entrevistas una cierta actitud defensiva que, en ocasiones, se reviste de ironía para expresar su queja por lo que consideran una presión excesiva e ilegítima sobre las ETN por parte de ONG, sindicatos y consumidores. De acuerdo con la valoración de los DIRSE, muchas de estas organizaciones se mueven con la idea maniquea de que las «empresas son malas por definición» y exigen a las empresas lo que ellas mismas no son capaces de cumplir.

Yo creo que en esto de la responsabilidad social se carga mucho a la empresa ¿no? Y, no. Yo creo que todas las instituciones deberían ser socialmente responsables, ¿no? Y digo instituciones, universidades, digo sindicatos, digo asociaciones civiles. Entonces, es muy fácil decir: «las empresas son las que tienen que ser socialmente responsables» iBueno! Yo creo que no. Yo creo que las empresas podemos tirar de una manera e impulsar la responsabilidad social, pero curiosamente los sindicatos predican más de lo que hacen (en sonrisa) en temas de

como una cita de autoridad por la joven asociación DIrse y porque uno de ellos, como hemos dicho, es considerado el decano de la Rsc en España. Asimismo, y como veremos, las premisas a las que hacemos referencia son refrendadas por el discurso empresarial construido por la élite empresarial española. 
responsabilidad social, aunque tienen una visión muy buena.Yo creo que cuando logren implantarla será una maravilla. Las ONG, yo creo que tendrían también que replantearse un poco su rol, su papel como entidades socialmente responsables [...] (SEFIN3).

Digo no al planteamiento que está haciendo mucha parte del tercer sector que es autoatribuirse la competencia de juzgar a las empresas, en exclusiva. Y yo digo, no. ¡Oiga! Amnistía Internacional no tiene ni capacidad moral ni jurídica ni de ningún tipo para juzgar a mi empresa, en sí mismo, como ente, o Cruz Roja, me da igual. Espérate que te pongo dos extremos que no tienen nada que ver, ¿no? Es decir, el tercer sector parece que se ha autoatribuido la posibilidad de ser el escrutador, pues no, no [...] (PEGA2).

En segundo lugar, otro indicio que nos permite interpretar que las empresas al utilizar el acrónimo Rc o al proponer una nueva nominación como sostenibilidad corporativa pretenden hacer algo más que diferenciarse de la acción social, es el uso peyorativo del adjetivo «buenismo» para referirse a aquellos planteamientos que consideran que las empresas deben devolver a la sociedad lo que esta les ha dado. Planteamientos que, de facto, fueron los que en los años veinte y treinta dieron a luz al concepto Rsc con el impulso de los economistas keynesianos y su apuesta por la institucionalización de medidas compensatorias al poder corporativo. La profesora Adela Cortina lo expresa de forma meridianamente clara en el siguiente pasaje:

El concepto de responsabilidad social nace en los años veinte del siglo pasado, con la siguiente idea: las empresas siempre gestionan de alguna manera recursos sociales y toda organización que gestiona recursos sociales tiene que devolver algo a la sociedad por ellos. Aparece entonces ese concepto de responsabilidad social que se vuelve a fortalecer en los años cincuenta, sobre todo cuando las grandes empresas norteamericanas demuestran que tienen un enorme poder en la vida social y aparece también la idea de que, a mayor poder, mayor responsabilidad (Cortina, 2010: 51).

El texto de Andreu y Fernández (2011) usado por la Asociación Española de Directivos de RSE está en clara sintonía con la máxima liberal que afirmaba el carácter corrosivo de los sentimientos -léase valores- en la economía y que era usada por Levitt (1958) para defenderse de la Rsc keynesiana en el ámbito académico anglosajón (Gil, 2016a, 2016b). Este sitúa en el plano de lo «irracional» $\mathrm{e}$ «ineficiente» aquellas argumentaciones que parten del convencimiento de que el poder de las transnacionales requiere de ciertos mecanismos que amortigüen y compensen sus efectos perversos (como la participación de los sindicatos y organizaciones sociales en los consejos de administración, el control de las retribuciones de directivos y consejeros, los límites a la acumulación, etc.). Por lo tanto, podemos decir que hay un cierre no solo a la identificación de la Rsc con la filantropía sino también con aquellas significaciones más (neo)keynesianas o socialdemócratas de 
la responsabilidad social de las empresas, que la conciben como la obligación de reparar un daño o cumplir una pena por él (Ricoeur, 1997).

En tercer lugar, y en clara consonancia con la expulsión de significados más sociales de la Rsc, tanto en la segunda como en la tercera premisa los autores justifican y defienden la legitimidad de la Rsc en su racionalidad con arreglo a fines, haciendo de la lógica del beneficio y la rentabilidad los principios que deben guiar cualquier iniciativa empresarial, incluida la RsC. La defensa del necesario retorno económico de la RSC entre las ETN se ha convertido en la mayor evidencia de honestidad empresarial y en la única garantía de que esta será una práctica veraz. Sin embargo, no siempre fue así, tal y como relata este DIRSE en el siguiente extracto:

Hace unos años en alguna universidad, en alguna conferencia, yo tenía la, no sé, la, la desfachatez - porque así se consideraba, yo nunca lo consideré una desfachatez- de decir que la RsC tenía que tener retorno para el negocio. En aquellos años la Rsc, casi decir que buscaba retorno para tu propia organización, es decir, que detrás de todo también había un fin egoísta, si se quiere llamarlo, o un profit... Otros colegas de otras empresas se escandalizaban. Decían: «Pero cómo te atreves a decir en público, ¿no? ¿Cómo te atreves?». Pero lo he creído siempre y, al final, ellos mismos están entrando por el aro. Diciéndolo pero sin decirlo, me da igual, ¿no? [...] Y esto es un poco así, si no queremos convertir a la Rsc en la asignatura «María» de las organizaciones o la metemos en nuestros planes de negocio y somos capaces de eso sea así, o si no lo que estamos haciendo o bien cosas por imagen o cosas desarticuladas respecto de la estrategia de negocio, y desde luego sin ningún retorno, ¿̨no? Y será más, si quieres, una posición cosmética y utilitarista que una posición efectiva (PEGAs2).

En definitiva, creemos poder afirmar que las coordenadas narrativas que permiten la construcción de la noción empresarial Rsc se edifican sobre unas fronteras visibles e invisibles, dichas y no dichas. Las primeras expulsan las significaciones filantrópicas que asocian la Rsc con la acción social, y las segundas, las altruistas que asocian la Rsc con la «diligencia en procurar el bien ajeno aún a costa del propio». Esta sofisticada estrategia de enmarque tiene la capacidad de equiparar la idea de que «la racionalidad económica debe ser controlada por la social» (derechos, regulación, impuestos, negociación colectiva, etc. - significante keynesiano-) con la de «la racionalidad económica debe controlar la social, pero ceder parte de sus beneficios» (donaciones, mecenazgo, acción social, caridad -filantropía empresarial-), tratándolas como igualmente ingenuas y fraudulentas por altruistas. ${ }^{13}$

13 Esta estrategia ha sido contestada no sólo por las organizaciones y académicos/as más próximos a un ideario de democracia radical, sino también por aquellos otros más cercanos al espacio político de la socialdemocracia. Concretamente, en 2014 la organización española Economistas sin Fronteras publicaba un dossier titulado «Rsc: Para superar la retórica», en el que escribían los que podrían considerarse los principales representantes españoles de la RSE que nosotros hemos llamado 


\subsection{Orden del discurso y aculturación}

La común comprensión de la RSC como una cuestión de negocios se construye no solo con unas fronteras narrativas concretas, sino también con una determinada organización de lo que se dice. En nuestro caso, este orden se lo otorga la puesta en juego de unos determinados atractores semánticos y el enlace entre ellos mediante hilos discursivos que integran y resignifican ideas y argumentaciones provenientes de la literatura gerencial y la crítica social (aculturación), ${ }^{14}$ tal y como hemos representado en la Figura 2.

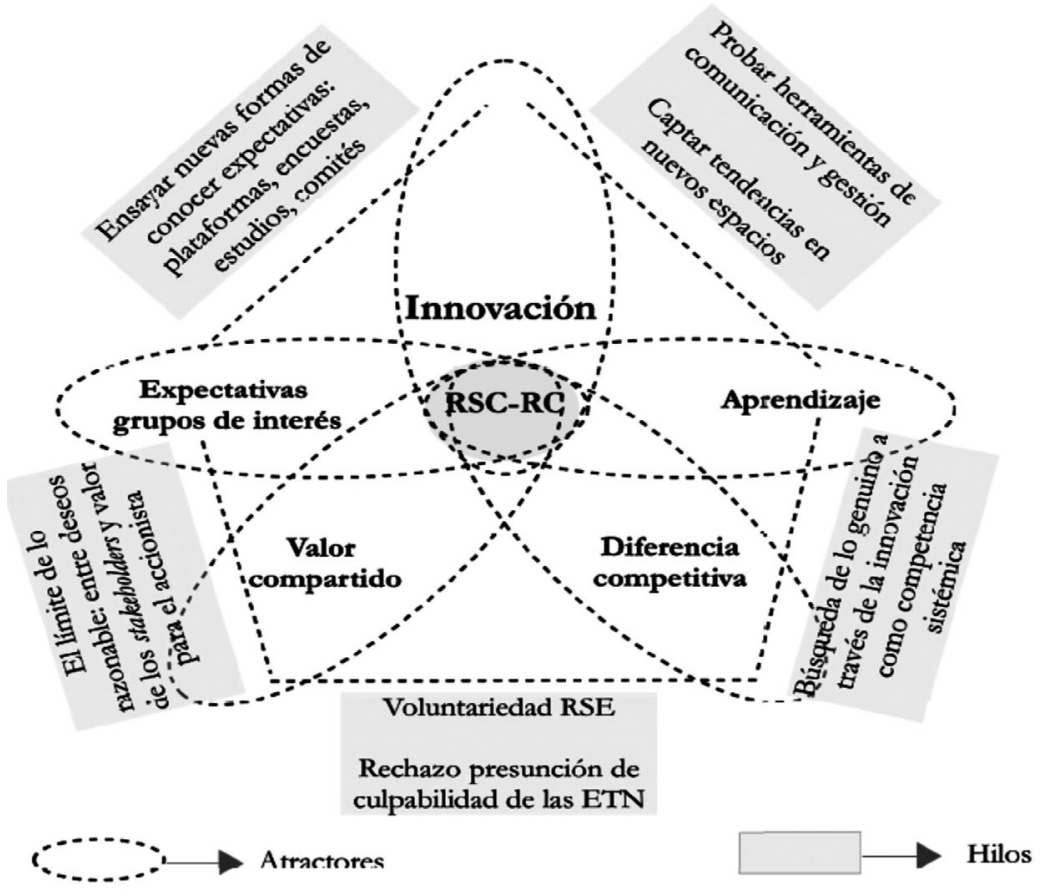

Figura 2

Responsabilidad social corporativa Atractores semánticos e hilos discursivos

keynesiana, criticando el uso instrumental y economicista que las empresas han dado a la RSC y reivindicando la necesidad de volver a hacer de la misma una cuestión social.

14 Como ha sido ejemplarmente analizado por Boltanski y Chiapello, en su ya clásica obra El nuevo espíritu del capitalismo, el proceso mediante el cual el capitalismo incorpora argumentos ajenos al mundo de la empresa y la ganancia para reforzar el compromiso social que lo legitima y sustenta es denominado «aculturación». 
Las referencias veladas y las similitudes manifiestas con el lenguaje de la innovación impregnan todo el discurso empresarial de la Rsc (Figura 2). Esta es presentada por los DIRSE y responsables de RSE como una forma de innovar en el modelo de negocio, es decir, en el marco conceptual o lógico que nos informa acerca de cómo una empresa crea, proporciona y obtiene valor. Lo que significa que la Rsc es para las empresas no solo una cuestión de negocios (business case), sino también un nuevo modelo de negocio. De esta manera, las empresas hablan de la responsabilidad corporativa como un proceso de creación que implica estar en continuo aprendizaje, ensayando y probando nuevas formas de medir y valorar las expectativas de los grupos de interés y de comunicar su información socialmente responsable. Además, supone una nueva cultura empresarial y un nuevo tipo de liderazgo, que impregna todo el modelo de negocio, y que reúne las condiciones necesarias para buscar entre toda la compañía esas prácticas genuinas que hacen que la empresa emprenda nuevos negocios competitivos, buenos para la corporación y buenos para la sociedad. Todo ello en un tono que convierte lo que, en principio, fue concebido como tragedia (el poder y el impacto de los negocios en las sociedades) en una aventura (la contribución de los negocios a los problemas de nuestras sociedades), emocionante pero realista, que rechaza la idea de su presunción de culpabilidad pero que, a su vez, acepta moderadamente la crítica.

El modo en que las empresas responden a las demandas y expectativas de los grupos de interés para terminar ofreciendo un producto y/o servicio socialmente responsable y empresarialmente rentable, es mediante el recurso a la innovación. La Rsc se ha convertido para las empresas en sinónimo de innovación social y sus esfuerzos se centran en consolidar un sistema de organización empresarial que sea capaz de hacer de ella una competencia sistémica. Para ello, en primer lugar, los directivos y profesionales de la RSC se convierten en «jardineros» capaces de hacer «aflorar» iniciativas que la corporación ya venía llevando a cabo y transformarla en un «caldo de cultivo» de iniciativas socialmente responsables.

Cuando nosotros empezamos a promover, desde aquí [departamento de rsc], todas las iniciativas relacionadas con nuestros compromisos de buen gobierno corporativo, medioambientales, sociales, entonces empezaron a entender [el resto de unidades corporativas] que muchísimas cosas que se estaban haciendo, desde hace mucho tiempo, en esta empresa no se ponían en valor; y nosotros lo que hicimos fue facilitar que afloraran muchas cuestiones que se hacían sin denominarlas responsabilidad social corporativa, o responsabilidad social empresarial, pero que esta empresa llevaba mucho tiempo llevándolas a cabo (CONEIN1). 
Creo que es tremendamente interesante y creo que es necesario entusiasmar a algunas personas de la organización, porque a base, de verdad, creer y sentir que todo esto es importante, se va generando un clima de responsabilidad en cada miembro de la empresa y va generando a su vez un cierto laboratorio o caldo de cultivo de sugerencias y de ideas, de trabajar, si se quiere, desde un espíritu responsable ¿no? (BIECON1).

Esta metáfora de la Rsc como vivero y el directivo como jardinero no es asunto baladí en el discurso que organiza la noción empresarial Rsc ni en la literatura de administración ni en la gestión de empresas. ${ }^{15}$ Como es de sobra conocido, desde la Segunda Guerra Mundial el mundo de la guerra y la máquina han sido utilizados como un referente teórico y moral en el pensamiento gerencial. No obstante, a partir de los años ochenta con la explosión de la producción flexible y la globalización, estas metáforas se vuelven demasiado rígidas para inspirar la organización y dirección de las ETN, y aparecen unas más líquidas relacionadas con el mundo de los organismos vivos, la cultura, el aprendizaje continuo, la navegación e incluso la danza, como es el caso de las propuestas por los profesores y gurús de la administración Richard Florida o Peter Senge (Alonso y Fernández, 2013).

En concreto, Senge afirmaba a finales de los años 90 que «los gerentes tienen que dejar de pensar como mecánicos, y actuar como si fueran jardineros» (Senge, 1990: 34) para lograr corporaciones capaces de innovar y estar en el cambio, unas ideas que se emparentan de un modo evidente con la propuesta de la «dirección empresarial innovadora» de Drucker (1986 en Fernández Rodríguez, 2004). ${ }^{16}$ Este papel de «directivo jardinero» supone el destierro de la figura del mito del héroe y la bienvenida a un tipo de liderazgo que sea capaz de crear una comunidad de líderes comprometida con el cambio social, la creatividad y el aprendizaje. Idea que está en clara consonancia con las argumentaciones que aducen nuestros entrevistados para justificar la conveniencia de la RSC como factor de innovación y con el tono aventurero, pero realista, que las sustenta.

Respecto a la conveniencia de la innovación, ya hemos dicho que está concebida como un requisito imprescindible de una RSC capaz de generar valor tanto para los grupos de interés como para la empresa. Con relación

15 La figura del «jardinero» tampoco pasa desapercibida para el pensamiento económico liberal. Von Hayek escribía: «La actitud del liberal hacia la sociedad es como la del jardinero que cultiva una planta, el cual, para crear las condiciones más favorables a su desarrollo, tiene que conocer cuanto le sea posible acerca de su estructura y funciones» (Von Hayek, 2008: 58-59).

16 La obra de Peter Drucker es imprescindible para comprender cómo la figura del emprendedor y de la innovación se han consolidado en la literatura gerencial como garantías de supervivencia y crecimiento económico en la era del capitalismo postfordista. En ellas el conocimiento se vuelve el factor de producción más importante para el éxito económico (Fernández Rodríguez, 2004). 
al papel de los stakebolders, estos son considerados como la verdadera materia prima de la innovación. Sus expectativas son tratadas por el empresariado entrevistado como una fuente constante de ideas, en las que el diálogo con estos actores aparece como un mecanismo imprescindible para alimentar de nuevas ideas el circuito de la innovación. Y es que, tal y como reconoce Juan Alfaro de la Torre, Secretario General del Club de Excelencia en Sostenibilidad y Director del Programa Superior de Responsabilidad Corporativa del Instituto de Empresa:

Las expectativas de estos grupos de interés deben ser una fuente constante de innovación para la compañía, de ahí la insistencia en que el diálogo forme parte de la estrategia de la empresa. En estos momentos se observa que este tipo de plataformas de diálogo saca a la luz un gran número de expectativas de los grupos de interés sobre la actividad de la empresa y, por tanto, supone una fuente inagotable de ideas (Alfaro, 2007: 273).

El diálogo con los grupos de interés, sean del tipo que sean, no es la única fuente «inagotable de ideas» para hacer desarrollar la innovación de la compañía, sino también el circuito de asociaciones y foros empresariales creados alrededor de la Rsc, los cuales funcionan como una red de apoyo y socialización del discurso del mundo de los negocios en torno a este tema. El siguiente extracto es muy clarificador al respecto y nos da pistas sobre cómo funcionan en España los grupos privados de cooperación interempresarial de RSE:

[...] Bueno, pues y también nos ha venido bien [la Rsc] para, incluso, relacionarnos entre nosotros y conocernos mejor.

Entrevistadora: Sí, finalmente se ha creado como una [red social].

Respuesta: sí, dentro de otras redes que ya existían, ¿no? Pero, es verdad, que bueno los que trabajamos en este sector, vamos, en esta área de trabajo de la RSE, que cuando ya nos encontramos en foros y ya cuando somos habituales pues es como una camaradería y, bueno, han surgido colaboraciones (CONEIN2).

Cuando las empresas hablan de incluir en la ecuación de la rentabilidad empresarial a los grupos de interés, también expresan que serán ellas las que decidirán con qué grupos de interés relacionarse y cómo integrar sus demandas en la estrategia de negocio. Las respuestas relativas a las relaciones que las empresas mantienen con los grupos de interés se suelen inscribir en el hilo discursivo de «lo razonable».Así, según la élite empresarial española estudiada, lo ajustado a razón es responder ante estos stakebolders sin olvidar que la empresa no les otorga derechos, sino que les da permiso para participar en el diálogo con ella, la cual tiene dueños y objetivos pro- 
pios.Y lo proporcionado es recibir a los grupos de interés más críticos con los que las empresas no se suelen entender y escucharlos, para hacer del encuentro una reunión fructífera que sirva para seguir mejorando, pero sin olvidar su problema de representatividad y sin ceder a su ataque al sistema de libre empresa.

Digamos que lo razonable es establecer relaciones con los grupos de interés que decidan mantener los asuntos económicos fuera de las competencias democráticas y que establezcan relaciones «constructivas» sin cuestionar el principio de rentabilidad de lo social ni la soberanía absoluta de la empresa en las decisiones de su negocio, es decir, que no hagan de la RSC una «carga».

Entrevistadora: Ha habido por parte de los sindicatos más activos y de la gente más activa en torno a la RSE cierto malestar porque, según estos, la verificación de la RSE no debe ser únicamente la verificación del informe de responsabilidad corporativa, sino que es necesario establecer algún tipo de control, de auditoría, que sea capaz de rendir cuentas, de demostrar que lo que la empresa dice que están haciendo se haga. Entonces ellos planteaban también la posibilidad de participar en este tipo de monitoreo, de observancia o de control, sindicatos y algún tipo de ONG...

Respuesta:Ya, pero ¿por qué solo para responsabilidad corporativa?, porque, por ejemplo, el informe al gobierno corporativo nadie lo verifica. Ahora nadie lo ha verificado ni nada, de medio ambiente. O sea, yo creo que pedirle tanto, tanto, tanto, al final acaba siendo una carga. O sea, sí me parece bien que haya un cierto control, pero, quizás, eso, con que tú lo cuentes y esté verificado en la Memoria, con eso podría ser suficiente. Porque lo puedes hacer con todo y con las demás cosas no se hace (CONEIN1).

En el relato de las ETN hay una continua tensión entre el reto o el desafío que supone asumir un comportamiento socialmente responsable de estas características y las limitaciones con las que la empresa se encuentra para llevarlo a cabo. Esta tensión se traduce en una especie de franqueza cautivadora, como diría Žižek (2003), que admite los problemas que acarrean los intereses que defiende sin que este reconocimiento suponga motivo alguno para invalidar dichos intereses. A este tono colectivo que, al fin y al cabo, es una práctica discursiva más, lo hemos llamado la «franqueza de la innovación».

La «franqueza de la innovación» está muy relacionada con el atractor «aprendizaje» porque permite interpretar los límites de la RSC como parte de un proceso en el que se está, que admite idas y venidas, incluso errores, pero que no tolera la inacción o la resignación. Por lo tanto, esta práctica discursiva es desempeñada por las empresas cuando las contradicciones entre los principios que dicen guiar su RSC y la práctica real son evidentes. 
Concretamente, en las entrevistas analizadas hemos detectado tres tipos de justificaciones que los profesionales ponen sobre la mesa para explicar esta distancia. Estas son: las que se basan en el carácter utópico del concepto rsc, las que asumen la complejidad del contexto socioeconómico en el que las empresas viven y las que aluden a los límites existentes en la atención a los grupos de interés.

Respecto a las justificaciones que se basan en el carácter utópico de la RsC, debemos decir que normalmente lo detectamos como un «no dicho» cuando las empresas hacen uso de coletillas como «estamos en el camino», «esto es como ir poniendo ladrillos en un muro», "vamos a ver qué es lo que sale de aquí», "estamos probando», «es un terreno de juego, en el que hay que jugar, no es claro, no hay pautas». Solo en un caso nos hemos encontrado con reconocimiento explícito de la imposibilidad de la Rse, tal y como se puede leer en el siguiente extracto:

\begin{abstract}
Entonces, creo que hay un grupo de compañías que estamos en ese proceso [en el de integrar la Rsc en la esencia del negocio], porque, además, yo soy de los que cree que, y esto tampoco lo diría ante un medio de comunicación, pero que no existe, que el concepto de empresa responsable frente a empresa no responsable es falaz, en el sentido de que no existe una sola empresa que sea responsable, no puede, quiero decir es un concepto utópico, utópico. Porque si todos entendemos lo que entendemos por la responsabilidad y sabemos que es tan amplia es prácticamente imposible que en organizaciones de 5.000 de 10.000 o 20.000 personas no haya nunca una sola persona que tome una pequeña decisión que no sea responsable. En todas las organizaciones las hay, las hay [asiente], en ese proceso en el que estamos ese grupo de compañías, ¿no? Trabajando yo creo que el enfoque no es soy responsable o no soy responsable, yo creo que el enfoque es estoy en el camino, en el cauce, o estoy en el aprendizaje, en el proceso y en la mejora (PEGAs2).
\end{abstract}

A pesar de que la persona entrevistada advierte del carácter privado de la confesión repitiendo que lo que dice no lo diría en los medios de comunicación, nos parece claro que si esta confesión no tuviese valor alguno dentro de su narración no la haría, sobre todo en un directivo que ha

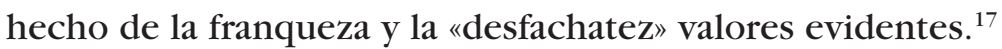

Esta cita nos parece especialmente significativa porque su carácter extremo nos permite ver mejor la estructura argumentativa de lo que hemos llamado la «franqueza de la innovación», y que no es otra cosa sino el modo

17 Consideramos que esta declaración sería considerada por el resto de entrevistados como un acto de "delincuencia discursiva», aunque en realidad es una afirmación nada novedosa. En los años ochenta el académico Thomas Jones defendía la importancia de introducir medidas en las corporaciones que las facultaran para «estar» en el proceso de la responsabilidad y no «ser» socialmente responsables, lo cual parecía ya por aquel entonces materialmente complejo y teóricamente inviable (Araque y Montero, 2006). 
en que las empresas responden a las contradicciones de la RSC sin despegarse de la visión que sostiene esta noción empresarial. Como podemos ver, el modo en que reconoce las limitaciones de la Rsc conjuga la aceptación de la imposibilidad de las ETN de asumir el control con la desconsideración del reconocimiento de la existencia de un centro de poder en las ETN, asimilando la corporación no como una entidad propiedad de accionistas y gestionada por directivos, sino como una corporación que es la suma de personas. Es decir, que la aceptación de los límites de la Rsc llega hasta donde el marco de la despolitización de la empresa lo permite, existiendo una evidente tensión entre la aceptación y la deformación de las críticas. ${ }^{18}$

Por otro lado, y de un modo más frecuente y explícito, existe en las narraciones de los profesionales de la Rsc cierto reconocimiento de la dificultad que impone el sistema socioeconómico para que las empresas puedan cumplir con el mandato de la responsabilidad social empresarial. De este modo nos encontramos, por ejemplo, con la aceptación una tanto cínica, pero sobre todo pragmática, de situaciones como las que se señalan:

- El reconocimiento de la imposibilidad de controlar en la cadena de suministro el uso de materias primas que provengan de zonas castigadas y/o protegidas medioambientalmente si se quiere competir dentro del mercado.

Por ejemplo, pues asegurar que ninguno de los cerdos que nosotros usamos de materia prima pues ha comido piensos producidos con algún cereal o soja que se haya producido en la selva de Brasil en zonas deforestadas, jno lo podemos hacer! [sin subir mucho el tono] ni está el estado, digamos, de nuestro negocio para empezar a implantar [...] Es, sin embargo, es de repente pretender, pretender que se cumplan unos estándares que son incumplibles, pues, pues, es muy difícil. ¡Ahora! ¿Hemos hecho algo? Sí hemos hecho algo, hemos comunicado a los proveedores, en determinadas ocasiones y un poco sesgadamente, en que tenemos interés en todo esto y que, por favor, nos informen de cuáles son sus políticas. (BIECON1).

- El reconocimiento velado de la negativa empresarial a exportar prácticas laborales y medioambientales similares en todos los lugares del globo ante la imposibilidad de hacerlo a coste cero, o sin que esta práctica te expulse del mercado, o suplantes la soberanía de los Estados, o que, incluso, sea perjudicial para los propios proveedores en países empobrecidos.

18 Una tensión que no es tan evidente en los informes de RSC, un género discursivo más próximo a la publicidad que a la rendición de cuentas. Muestra de ello es la denuncia del Observatorio de Rsc en su análisis de las memorias de Rsc de las empresas del IBEX 35 (2013), de la escasa neutralidad y equilibro de la información contenida en estos documentos. 
Entrevistadora: [...] Sí, bueno, lo que pasa es que bueno cuando en el Consejo de Lisboa aparece la RSC para hacer de Europa una de las economías más competitivas y basada en el conocimiento sí que se piensa bastante, en principio, en intentar exportar los estándares de protección del modelo social europeo, ¿no?

Respuesta: Sí, la pregunta es quién lo paga. A ver, yo solo te digo que no es fácil.Y lo que te digo también, es que si al final, la onu, ha sido incapaz a lo largo de su historia de que algo tan sencillo como la Declaración Universal de los Derechos Humanos tenga realidad, ¿por qué se les pide a las compañías si no lo han hecho los Estados? Es que es un poco complicado de entender. No te digo que las compañías no tengan que hacerlo, no te estoy diciendo eso.Te digo que planteemos algo de realidad geopolítica en esta historia, ¿entiendes? Cómo se les va a pedir a las empresas europeas que exporten al 100\% la legislación europea en aquellos países que sus parlamentos no han aprobado esa legislación. Es que, al final, te sitúas en una situación muy complicada. ¿Lo ves? (TECITEL1).

La rigidez en general, en general, [hace alusión de un modo velado a una ong que ha fiscalizado su cadena de producción y suministro] en lo que tiene que ver con la RSE, es también un problema, esto en el Tercer Mundo no se entiende, es perjudicial, esto de imponer parámetros al proveedor y si no lo hace lo echas, no está bien. Hay que darles pedidos a estas empresas proveedoras para que mejoren, para que introduzcan mejoras. Hay que decirles cómo mejorar y darles negocio. Estas mejoras hacen que los trabajadores de estos países quieran trabajar en estas empresas frente a otras en las que las condiciones laborales son peores y también vas creando un clima. España ha sido la China de Estados Unidos hasta los años cincuenta, también vinieron en su momento las multinacionales estadounidenses, es una evolución poco a poco... (BIECON3).

- El reconocimiento de la imposibilidad de ser coherente con los principios de la RSC en asuntos que reflejan las incoherencias de la sociedad, como es el caso de las retribuciones de los directivos empresariales, y frente a las cuales las corporaciones parecen tener un limitado margen de maniobra.

Y tercero, que es la más cuestionable, lo más moralmente aceptable, que efectivamente es un tema difícil, que casa difícil, casa difícil sí que es cierto, que un poco la explicación, que, que, al final hay que ser un poco pragmáticos, ¿no? pero un poco la realidad cuál es, es que el sistema que tenemos montado es un poco perverso, ¿no? No el sistema financiero, sino en general, o sea, tenemos un sistema montado, una sociedad, de que en algunas profesiones, no todas, pero en algunas, pues a personas con talento extraordinario, se les remunera de forma extraordinaria, ¿no? con resultados extraordinarios. Y eso pasa en la banca, pasa en los actores, pasa en los jugadores de fútbol, pasa en los pilotos de Fórmula 1, pasa en los cantantes, y pasa en muchos temas (SEFINI1).

- La defensa de la interpretación de la Rsc como una prueba de la licencia que la sociedad le otorga a las empresas para que generen beneficios, aunque reconozca por omisión que la redistribución de los mismos siga siendo un tema delicado o complicado que excede a la empresa. 
Entrevistadora: En esa responsabilidad social que ustedes desarrollan, ¿̇cuáles serían los elementos clave, centrales, que los diferencien y que definirían su concepto de la responsabilidad social?

Respuesta:Yo creo que lo específico puede ser algunas actuaciones que podamos hacer y que sean específicas por nuestro tipo de negocio, por nuestro tipo de actividad, porque que queramos ser más innovadores, porque queramos profundizar más, pero en cuanto a concepto claves yo creo que son los mismos para nosotros que para los demás. Vamos a ver, el convencimiento de que los beneficios, lo he dicho ya al principio, los beneficios son lícitos, una empresa su finalidad es generar un beneficio, no hablemos luego de su redistribución, pero generar un beneficio y el tema está en que la calidad de ese beneficio sea una forma determinada en cuanto a medio ambiente y... [...] (PEGAS1).

Lo que nos parece especialmente interesante de estos verbatims es su «cinismo pragmático» (Žižek, 2003), donde se reconoce, aunque de un modo más velado que revelado, la incapacidad estructural de mantener un comportamiento empresarial justo pero la posibilidad de desplegar un comportamiento responsable. Ello termina por dibujar en el discurso empresarial una imagen de las empresas como agentes económicos con un control limitado sobre las circunstancias, pero con la honradez suficiente como para reconocerlo y la iniciativa necesaria para responder ante ellas.

Este tipo de justificación que los profesionales de la RsC despliegan se sitúa en el hilo discursivo que se mueve entre los atractores aprendizaje, diferencia competitiva, valor compartido y expectativas de los grupos de interés que configuran la base del pentágono dibujado en la Figura 2. Con él las empresas huyen del argumento de la culpabilidad («las empresas son malas por naturaleza») y se sitúan en el de la complejidad («las empresas hacen lo que pueden») para justificar su modelo y noción de responsabilidad social empresarial. Este desplazamiento en las narraciones de las empresas de la culpabilidad a la complejidad creemos que es más un síntoma de una nueva estrategia discursiva que está por venir -y que se comienza a vislumbrar en el uso estratégico de las «historias corporativas»- que una práctica verdaderamente consolidada entre la élite empresarial española estudiada. ${ }^{19}$

De hecho, es cada vez mayor la presencia en la formación y contratación empresarial de servicios relacionados con la construcción y el uso de un

19 Los directivos y/o profesionales entrevistados elaboran historias y anécdotas que forman parte de su competencia discursiva y pragmática sobre RSC. Como resultado, nos encontramos con la historia de las tres reglas básicas, la historia de los tres pilares de la Rsc, la historia de las tres palancas o la historia de los ocho valores, entre otras. Todas ellas, a pesar de sus diferencias, enfatizan su carácter compartido (la gran mayoría de ellas incluye la expresión: «nosotros decimos») y se muestran altamente funcionales para adelantarse o enfrentarse a las críticas. 
«sistema corporativo discursivo» que permita elaborar una nueva narrativa empresarial, alejada de los relatos épicos, capaz de aceptar y defenderse ante la crítica social (Rubio, 2013, 2014a, 2014b). Por ejemplo, el think-tank Corporate Excellence-Centre for Reputation Leadership ${ }^{20}$ ofrecía un curso, en febrero de 2013, titulado Narrativa empresarial y Liderazgo Social, en el que exponía la necesidad de construir una nueva narrativa más honesta y capaz de movilizar transformaciones sociales, mediante la asunción de tres condiciones que, en nuestro caso, comenzamos a ver de forma clara en el discurso sobre Rsc de la élite empresarial española (Rubio, 2014a: 15). Estas son:

1) Aceptar que las empresas viven en la complejidad y que toda decisión relacionada con los recursos humanos, la inversión o el modelo energético, por ejemplo, lleva implícita una teoría del cambio social. «Lo que inmediatamente lleva implícito que algunas personas o agentes se posicionen para ayudarte, alinearse o adherirse al devenir del modelo.Y, por supuesto, también debemos asumir que siempre se provoca la aparición de oposición, críticas y detractores, aunque el modelo escogido sea responsable y busque un bien colectivo".

2) Huir de «los relatos épicos» hacia «las argumentaciones honestas que conmueven e ilusionan desde su trascendencia, convicción y compromiso».

3) Entender que construir un sistema discursivo corporativo es más fácil de lo que parece, ya que la empresa cuenta con todos los recursos que necesita. "Aunque no lo hayamos sistematizado ni profesionalizado antes, el sustrato y las semillas están.Y como son un activo de gran valor, está claro que siempre tenemos margen para fortalecer nuestras capacidades de gobernanza. Solo deberíamos dedicarnos a nosotros mismos un poco más de tiempo, y, si se me permite, escucha y cariño. Es decir, itiempo para regar nuestro propio jardín!» (Rubio, 2014a: 15).

Como vemos, la apuesta de la profesora Rubio, y de buena parte del storytelling y las relaciones públicas corporativas (Arthur Page Society, 2012; Salmon, 2008), parece sostenerse en la creación de relatos que sean capaces de aceptar la crítica - e incluso el conflicto ideológico- y construir una nueva empresa capaz de enfrentarse a los nuevos retos del siglo xxi. Para ello, el estudio de los repertorios críticos es cada vez más necesario, tal y como argumenta Rubio (2014b):

en un futuro no muy lejano la sociedad no solo nos impelerá [a las empresas] hacia la gestión responsable de nuestra huella ecológica y del entorno ambiental. Nos demandará que rindamos cuentas sobre el efecto que nuestra actividad tiene en la lengua de un te-

20 Este laboratorio de ideas es fruto de la fusión del Foro de Reputación Corporativa (constituido en 2002) y el Instituto de Análisis de los Intangibles (creado en 2004). Fue fundado por Bвva, CaixaBank, Iberdrola, Repsol, Santander y Telefónica y cuenta con la asociación de empresas relevantes en el ámbito público y privado. 
rritorio, en la convivencia de una ciudad, en las enfermedades de las que somos origen como el stress profesional, o en la promoción de las ciberlibertades, por poner solo un par de ejemplos sencillos que alterarán también los escenarios de gobernabilidad de nuestra actividad. Nos veremos confrontados claramente ante situaciones que son una auténtica preocupación social, como la pobreza energética.Y se nos reclamará, tal vez, que seamos capaces de presentar un Balance del Bien Común. En escena ya están presentes conceptos con los que debemos aprender a relacionarnos: procomún, colectivo, colaborativo, código abierto, consumo responsable, cocreación, cooperación, inteligencia crowd, disruptivo, libre, financiación colectiva... Incluso deberíamos estar alerta y no despreciar las aportaciones y propuestas de los movimientos sociales en los últimos años, ya que como recogen Mateos y Sanz, y destaca el sociólogo Manuel Castells, «analizar los movimientos sociales es fundamental - más en una coyuntura como la actual- habiéndose constituido históricamente en palancas de cambio social» y de anticipación de valores.

Consecuentemente, consideramos que la incipiente franqueza que hemos detectado en el discurso empresarial sobre la Rsc se desarrollará mediante la inclusión discursiva de argumentos y tácticas que sean capaces de enfrentarse a cuestiones que en las entrevistas analizadas han sido connotadas como irrazonables: aquellas que tienen que ver con la democracia económica y la justicia social en el contexto del capitalismo creativo. Cuestiones que, por otro lado, ya han sido literalmente aculturadas por el lenguaje propio del management mediante la retórica de la innovación (Alonso y Fernández, 2013).

\section{CONCLUSIONES}

Para imponer un determinado sentido de la noción Rsc los profesionales empresariales trazan las coordenadas narrativas desde las que se va a situar la conversación y levantan las fronteras que van a expulsar aquellos significados que no forman parte del ideario empresarial construido en torno a la Rsc. Como hemos visto, esas fronteras repelen en un plano manifiesto aquellas significaciones vinculadas al campo semántico de la caridad y en otro velado a las relacionadas con la compensación.

Con este ejercicio de «expulsión» discursiva, la élite empresarial española connota de ingenuas y fraudulentas tanto la idea de que «la racionalidad económica debe controlar la social, pero ceder parte de sus beneficios» (donaciones, mecenazgo, acción social, caridad -filantropía empresarial-) como la de que «la racionalidad económica debe ser controlada por la social» (derechos, regulación, impuestos, negociación colectiva, etc. -significante keynesiano-). 
Asimismo, la élite empresarial española establece un determinado orden del discurso que incorpora a la aculturación de determinadas críticas, el protagonismo de la innovación como símbolo. Dentro de este orden, los directivos aparecen como «jardineros», capaces de crear una empresa y un grupo humano creativos, que responden a las expectativas de los grupos de interés dentro de las posibilidades estructurales que la compleja realidad global impone. Este convencimiento colectivo de la élite empresarial española, incluye lo que parece ser una nueva identidad empresarial, que se construye en la tensión entre el reconocimiento, explícito y velado, de los límites estructurales que el «sistema» impone y la defensa de la presunción de complejidad de las empresas. Esta nueva identidad, que toma cuerpo en lo que hemos llamado la franqueza de la innovación y hemos calificado de cínica pragmática, es probable que incluya la aculturación de nuevas formas de organizar y pensar lo económico, como todas aquellas propuestas relacionadas con el bien común o la economía colaborativa. No obstante, y como hemos señalado en el cuerpo del texto, esta interpretación requiere de una validación mayor, que deberá ser asumida en futuras investigaciones.

\section{BIBLIOGRAFÍA}

AlBAREDA, L. (2009): La contribución de las autoridades privadas a la gobernanza global: las élites empresariales en las iniciativas de responsabilidad social de la empresa, Barcelona, Universidad Autónoma de Barcelona.

Alfaro, J. (2007): «Gestión estratégica» en RACEF (2007): La responsabilidad de la empresa: propuesta para una nueva economía responsable de la empresa responsable y sostenible, Madrid, Real Academia de Ciencias Económicas y Financieras.

Alonso, L. E. (2013): «La sociohermenéutica como programa de investigación en sociología», ARBOR, Ciencia, Pensamiento y Cultura, 189(761), pp. 1-15.

Alonso, L. E. y Fernández, C. J. (2013): Los discursos del presente. Un análisis de los imaginarios sociales contemporáneos, Madrid, Siglo XXI.

Álvarez-Uria, F. y Varela, J. (2004): Sociología, capitalismo y democracia, Madrid, Morata.

Ancos, H. y SÁnchez-Urán, Y. (2013): «Marco normativo de la responsabilidad social empresarial» en SÁnchez-Urán, Y. (dir.) y GraU, M.A. (coord.): Responsabilidad social de las organizaciones. Una perspectiva jurídica 
en el marco de la economía sostenible en la Unión Europea, Madrid, Grupo5.

Andreu, A. y Fernández, J. L. (2011): «De la rsC a la sostenibilidad corporativa: una evolución necesaria para la creación de valor», Harvard Deusto Business Review, 207, pp. 4-21.

Antaki, C. H., Billig, M., Edwards, D. y Potter, J. (2003): «Análisis del Discurso implica analizar: crítica de seis atajos analíticos», Athenea Digital,3, pp. 14-35.

Araque, R. A. y Montero, M. J. (2006): La responsabilidad social de la empresa a debate, Barcelona, Icaria.

Arthur Page Society (2012): Building Believe: A new Model for Activating Corporate Character \& Authentic Advocacy. Disponible en: http:// www.awpagesociety.com/wp-content/uploads/2012/03/Building-Belief-New-Model-for-Corp-Comms-2012.PDF [Consultado el 7 de diciembre de 2016]

Barañano, M. (2009): «Contexto, concepto y dilemas de la responsabilidad social de las empresas transnacionales europeas: Una aproximación sociológica», Cuadernos de Relaciones Laborales, 27(1), pp. 19-52.

- (2010): «Responsabilidad Social y Regulación Estatal en el marco del transnacionalismo y la pluralización normativa», en BERIAIN, J. y SÁNCHEZ DE LA YNCERA, I. (eds.) (2010): Sagrado/Profano. Nuevos desafíos al proyecto de la modernidad, Madrid, cIs.

Blowfield, M. y Murray, A. (2008): Corporate Responsibility: A Critical Introduction, Oxford, Oxford University Press.

Boltanski, L. y Chiapello, E. (2002): El nuevo espíritu del capitalismo, Madrid, Akal.

Bonilla-Castro, E. y Rodríguez, P. (2005): Más allá del dilema de los métodos. La investigación en ciencias sociales, Bogotá, Grupo Editorial Norma.

Conde, F. (2009): Análisis sociológico del sistema de discursos, Madrid, cIsCuadernos Metodológicos.

Cortina, A. (2010): Las raíces éticas de la democracia, València, Publicacions de la Universitat de València.

DIRSE (2014): Repensar la responsabilidad social. Una mirada desde los DIRSE, Madrid, Asociación española de Directivos de Responsabilidad Social (DIRSE).

Domínguez, R. (2012): «La dimensión internacional de la Responsabilidad Social de la Empresa», en López, L. (coord.): Autonomía y Heteronomía en la Responsabilidad Social de la Empresa, Granada, Comares. 
Dyer, J. H., Gregersen, H. B. y Christensen, C. M. (2012): El aDN del innovador. Claves para dominar las cinco habilidades que necesitan los innovadores, Barcelona, Planeta.

FERnÁNdez Rodríguez, C. J. (2007): El discurso del Management: tiempo y narración, Madrid, Centro de Investigaciones Sociológicas.

- (2004): Las transformaciones del discurso del management. Un análisis sociológico de los textos fundamentales de la gestión empresarial, Madrid, Universidad Autónoma de Madrid.

FLICK, U. (2014): La gestión de la calidad en investigación cualitativa, Madrid, Morata.

Foucault, M. (1973): El orden del discurso, Barcelona, Tusquets.

- (2007): Nacimiento de la biopolítica. Curso en el Collège de France (1978-1979), Buenos Aires, Fondo de Cultura Económica.

GALBRAITH, J. K. (1952): American capitalism: the concept of countervailing power, Boston, Houghton Mifflin.

GibSON, R. y SKARZYNSKI, P. (2012): Innovación en el ADN de la organización. El modelo que transforma la manera en que su empresa innova, México DF, Cengage Learning.

GIL, G. (2016a): Revisión crítica de la noción empresarial "Responsabilidad Social Corporativa». Una aproximación genealógico-discursiva, Las Palmas de Gran Canaria, ulPGC.

- (2016b): "Análisis genealógico de la noción Responsabilidad Social Corporativa construida por el mundo de los negocios. Parte I: Producción Académica y Escuelas de Negocios», en el XII Congreso Español de Sociología. Comunicación oral en el Grupo de Trabajo, 31 (Sociología Económica), 1 de julio de 2016, Gijón, España.

GLASER, B. y A. STRAuss (1967): The discovery of grounded theory: strategies for qualitative research, New York, Aldine Publishing Company.

Gordo, A. J. (2008): "Análisis del discurso: los jóvenes y las tecnologías sociales», en Gordo, A. J. y Serrano, A. (coords.): Estrategias y prácticas cualitativas de investigación social, Madrid, Pearson-Prentice Hall.

GuIlléN, M. F. y GARcíA, E. (2007): «La expansión internacional de la empresa española: una nueva base de datos sistemática», ICE, (839), pp. 23-34.

Gutiérrez Brito, J. (2009): «Introducción a la lógica del análisis del discurso», en CALlejo, J. (coord.): Introducción a las técnicas de investigación, Madrid, UNED.

GutiérRez, M. (21 de octubre de 2015): rSC desde el core business, ¿o desde el cuore business? Disponible en: http://diarioresponsable.com/ 
opinion/19206-mercedes-gutierrez [Consultado el 7 de diciembre de 2016]

ÍñIGUeZ, L. (2011):Análisis del discurso. Manual para las ciencias sociales, Barcelona, Editorial uoc.

LACLAU, E. (2005): La razón populista, Buenos Aires, FCE.

Laclau, E. y Mouffe, C. (1987): Hegemonía y estrategia socialista. Hacia una radicalización de la democracia, Madrid, Siglo XxI.

LevitT, T. (1958): «The dangers of social responsibility», Harvard Business Review, 36, pp. 41-50.

Lozano, J., Albareda, L., Ysa, T., Roscher, H. y Marcuccio, M. (2005): Los gobiernos y la responsabilidad social de las empresas. Políticas públicas más allá de la regulación y la voluntariedad, Barcelona, Granica.

MaIRA, M. M. (2010): «La Responsabilidad Social de las Empresas Transnacionales con sede central en España: ¿Neopaternalismo industrial o globalización de derechos?», Sociología del Trabajo, 69, pp. 95-119.

- (2012): La dimensión internacional de la responsabilidad social empresarial: un campo de negociaciones y luchas entre distintas instituciones y actores, Madrid, UCM.

MaIRA, M. M. y GIL, G. (2011): «Los actores ante la responsabilidad social de las empresas transnacionales con sede central en España: posiciones discursivas y prácticas implementadas", en Aparicio, J. y Valdés, B. (dir.) (2011): La responsabilidad de las empresas en España: concepto, actores e instrumentos, Albacete, Editorial Bomarzo.

Matten, D. y Moon, J. (2008): "Implicit" and "explicit” CSR:A conceptual framework for a comparative understanding of corporate social responsibility», Academy of Management Review, 33(2), pp. 404-424.

Observatorio de la Responsabilidad Social Corporativa (2013): «La rsc en las Memorias Anuales incluidas en el IBEX 35. Análisis del ejercicio 2013». Disponible en: http://www.observatoriorsc.org/Informe_memoriasRSC_ibex_2013_completo.PDF [Consultado el 7 de diciembre de 2016]

Patton, M. Q. (1990): Qualitative Evaluations Methods, California, Sage Publications.

Perdiguero, T. (2008): «Responsabilidad social de las empresas, desarrollo sostenible y políticas públicas», en Responsabilidad Social de las Empresas. Foro de Expertos. Informe sobre aspectos sociales y medioambientales. Diálogo social. Consejo Estatal, Madrid, Ministerio de Trabajo y Asuntos Sociales. 
Porter, M. y Kramer, M. (2006): «Strategy and Society:The link between competitive advantage and Corporate Social Responsibility», Harvard Business Review, 84, pp. 78-92.

- (2011): «La creación de valor compartido: cómo reinventar el capitalismo y liberar una oleada de innovación y crecimiento", en Harvard Business Review (Edición América Latina), 89(1), pp. 31-49.

RAPLEY, T. (2014): Los análisis de la conversación, del discurso y de documentos en Investigación Cualitativa, Madrid, Ediciones Morata.

Ricoeur, P. (1997): El concepto de responsabilidad. Ensayo de análisis semántico. Lo justo, Buenos Aires, Editorial Jurídica de Chile.

Rubio, L. (2013): Narrativa empresarial y Liderazgo Social. Equipo Sinergia. Curso organizado por Corporate Excellence en febrero de 2013. Disponible en: http://www.sinergiavalue.com/sites/default/files/Dossier_\%20 Narrativa\%20empresarial\%20y\%20Liderazgo\%20Social\%20-\%20SV\%20 Corporate_0.PDF [Consultado el 7 de diciembre de 2016]

- (2014a): «Sistema discursivo corporativo: herramienta de liderazgo y gobernanza corporativa», en Harvard Deusto Business Review, 239, pp. 6-15.

- (2014b): Nuevos liderazgos. Nuevas herramientas de gobernanza empresarial. Corporate Discourse \& Leadership Program. Disponible en: http://www.sinergiavalue.com/sites/default/files/Corporate\%20Discourse\%20\&\%20Leadership\%20Program\%20-\%20Sinergia\%20Value_0. PDF [Consultado el 7 de diciembre de 2016]

SAlmon, C. (2008): Storytelling. La máquina de fabricar bistorias y formatear las mentes, Barcelona, Atalaya.

SEnge, P. (1990): La Quinta Disciplina. Cómo impulsar el aprendizaje en la organización inteligente, Madrid, Ediciones Juan Granica.

SKLAIR, L. (2001): The transnational capitalist class, Oxford, Blackwell.

VAN DIJK, T.A. (2000) (comp.): El discurso como estructura y proceso, Barcelona, Gedisa.

Von HAYEK, F. (2008): Camino de servidumbre: Textos y documentos. Disponible en: http://www.elcato.org/sites/default/files/camino-de-servidumbre-libro electronico.PDF [Consultado el 7 de diciembre de 2016]

WeTHERELL, M. (2001): "Themes in discourse research: the case of Diana». en

Wetherell, M., Taylor, S. y Yates, S.J. (eds.): Discourse Theory and practice: $A$ Reader, London, Sage.

ŽIžEK, S. (2003): Ideología. Un mapa de la cuestión, México DF, FCE. 